\title{
BOAS PRÁTICAS DE FABRICAÇÃO E A MELHORA DA QUALIDADE NA AGRICULTURA FAMILIAR: ESTUDO DE CASO COM PEQUENOS PRODUTORES DE CACHAÇA
}

\author{
Maria Cristina Meneghin ${ }^{1}$ \\ Ricardo Augusto Bonotto Barboza ${ }^{2}$ \\ Geralda Cristina De Freitas Ramalheiro ${ }^{3}$ \\ Helena Carvalho De Lorenzo
}

Resumo: As Boas Práticas de Fabricação (BPF) estabelecem princípios gerais em todas as etapas da produção de alimentos e bebidas, sendo necessária para a manutenção da qualidade da produção, para a redução de perdas de processo, para conferir maior competitividade no mercado de bebidas e para garantir a qualidade, identidade e padronização do produto. Este trabalho avaliou a influencia da implantação de BPF na qualidade sensorial e físico-química de cachaças produzidas no Estado de São Paulo através de interação Universidade-empresa. Conclui-se que a interação Universidade-empresa implicou em melhorias no processo produtivo que foram refletidas na qualidade sensorial e físico-química da bebida.

Palavras-chave: Agricultura familiar; Boas Práticas de Fabricação; Qualidade.

\footnotetext{
${ }^{1}$ Pesquisadora Doutora, Faculdade de Ciências Farmacêuticas - UNESP, Araraquara. E-mail: babim@sirtunesp. com.br

${ }^{2}$ Professor Doutor, Universidade de Araraquara, Araraquara. E-mail: bonotto@bol.com.br

${ }^{3}$ Mestranda, Universidade Federal de São Carlos (UFSCar). E-mail: geralda.ramalheiro@gmail.com

${ }^{4}$ Professora Doutora, Universidade de Araraquara.E-mail: helenadelorenzo@gmail.com
} 
Abstract: As Boas Práticas de Fabricação (BPF) estabelecem princípios gerais em todas as etapas da produção de alimentos e bebidas, sendo necessária para a manutenção da qualidade da produção, para a redução de perdas de processo, para conferir maior competitividade no mercado de bebidas e para garantir a qualidade, identidade e padronização do produto. Este trabalho avaliou a influencia da implantação de BPF na qualidade sensorial e físico-química de cachaças produzidas no Estado de São Paulo através de interação Universidade-empresa. Conclui-se que a interação Universidade-empresa implicou em melhorias no processo produtivo que foram refletidas na qualidade sensorial e físico-química da bebida.

\section{Introdução}

Acachaça é a bebida destilada, mais consumida no Brasil ea quarta no mundo (MONTEIRO et al., 2013; BORTOLETTO; ALCARDE, 2015; SANTIAGO et al., 2015), é uma bebida tipicamente brasileira, que vem conquistando espaço no mercado nacional e internacional (CARNEIRO et al., 2010; OLIVEIRA et al. 2012) e cuja produção movimenta a economia nacional. Estima-se que 40 mil produtores sejam responsáveis por mais de 5.000 marcas diferentes de aguardentes de cana de açúcar; geram 600 mil empregos diretos e indiretos e faturam uma receita total de US \$ 6 bilhões por ano.

Anualmente, cerca de 1,7 bilhão de litros de aguardente de cana-deaçúcar e cachaças são produzidos no Brasil. No entanto, menos de $1 \%$ desta produção é exportada. Uma das razões que impedem a exportação de cachaça é a falta de qualidade e padronização (SOUZA et AL., 2013; BARBOZA; BOSCO, 2015; BORTOLETTO; ALCARDE, 2015). Assim, delimita-se que a cachaça de alta qualidade deve atingir determinados parâmetros químicos para não representar um perigo para a saúde se consumido moderadamente (MONTEIRO et al., 2013; ANJOS et al., 2011; BRASIL, 2005; ABRADE, 2013 BORTOLETTO; ALCARDE, 2015; SEBRAE, 2015).

Nesta contextualização, um fato que chama a atenção, é a existência de cachaça produzida artesanalmente e cachaça produzida industrialmente. Salienta-se que, aproximadamente, $75 \%$ da produção nacional de cachaça é realizadas em empresas industriais, cuja produção se dá grande escala, pelo uso de leveduras prensadas no processo de fermentação e por destilação em colunas contínuas de aço inox. Por outro lado, a produção das cachaças denominadas de artesanais ou de alambique é de apenas 300 milhões de litros anuais, cuja produção é realizada em pequenas destilarias, que utilizam leveduras naturais na fermentação e que destilam em alambiques de cobre separando as frações do destilado (PEREIRA, 2007; BARBOZA et al., 2010; OLIVEIRA et al. 2012).

Nota-se que a produção artesanal delineia-se como um seguimento de produto importante. O mesmo é composto por produtores distribuídos em dois grupos: o das empresas regularizadas e o das informais. Essas últimas caracterizam-se por serem desarticuladas e por não apresentarem regras de convivência com a concorrência. Sendo assim, partem para a competição predatória, não se preocupando com a qualidade do produto produzido e vendendo muitas vezes até por preços abaixo do custo de produção (BARBOZA. BOSCO, 2015). Machado e colaboradores (2014) observam que os produtores clandestinos trabalhram em condições precárias, utilizando materiais que são inadequadas para a produção de cachaça de alta qualidade, tais como recipientes de plástico, alambiques de aço inoxidável e tanques de concreto ou amianto, condutas que podem comprometer a produção de uma bebida de alta qualidade, facilitando a contaminação e o não-atendimento aos requisitos da legislação nacional, já que padrões de identidade e qualidade foram estabelecidos para aguardentes de cana de açúcar e cachaça no Brasil, por meio do decreto $\mathrm{n}^{\circ} 4.851 / 2003$ (BRASIL, 2005).

O principal objetivo deste decreto é padronizar a composição química dessas bebidas, a fim de proteger a saúde dos consumidores. Por conseguinte, estabelece os limites mínimos e máximos para os componentes voláteis não alcoólicas, assim como os contaminantes orgânicos e inorgânicos que podem estar presentes nas bebidas. Adicionalmente, no Brasil, o setor de produção de cachaça vem desenvolvendo programas de qualidade para a bebida, com o objetivo de ampliar o mercado interno e melhorar as exportações(FERNANDES et al., 2005; ALBUQUERQUE et al., 2006; LOUREIRO, 2008; PRIBANIC, 2011; OLIVEIRA, 2012). Em consonância com esses programas, a qualidade da bebida é supervisionada por órgãos públicos, como a Agência Nacional de Vigilância Sanitária (ANVISA) e o Ministério da Agricultura, Pecuária e Abastecimento (MAPA). Contudo apesar da legislação, dos programas de qualidade e da supervisão, a produção pode desviar-se das normas de qualidade ou pode ser fraudulenta (RODRIGUES et al., 2016).

Este estudo teve como objetivo avaliar a qualidade da cachaça produzida localmente, tendo como parâmetro as condições higiênico-sanitárias de micro e pequenas indústrias de cachaça de alambique do Estado de São 
Paulo por meio da aplicação de questionários e visitas técnicas in loco para avaliar a relação das Boas Práticas de Fabricação com a qualidade físicoquímica e sensorial das cachaças produzidas.O artigo foi estruturado em 5 seções além desta introdutória. Inicialmente faz-se uma apresentação das características da cachaça, sequencialmente discute-se a aplicação do conceito de qualidade na fabricação da cachaço logo depois, indica-se a metodologia utilizada na condução da pesquisa, os resultados alcançados e por fim, elabora-se as conclusões finais da pesquisa.

\section{Cachaça: a bebida brasileira}

Conhecida como a mais brasileira de todas as bebidas, a cachaça tem apresentado crescimento no mercado internacional e tem sido o terceiro maior destilado do mundo. Mais de cinco mil marcas e 30 mil empresas fabricam cachaça em todo o país, caracterizando-se em empresas familiares, regionais e muitas delas, de pequeno porte (ASSOCIAÇÃO BRASILEIRA DE BEBIDAS - ABRABE, 2013). Sua história se confunde com a própria história do Brasil, tendo sido a primeira bebida destilada na América Latina, descoberta entre os anos 1534 e 1549, durante o processo de produção do açúcar. Ali surgia a aguardente de cana genuinamente brasileira, posteriormente denominada cachaça (ABRABE, 2013).

Cachaça é a denominação típica e exclusiva da aguardente de canade-açúcar produzida no Brasil, com graduação alcoólica de trinta e oito a quarenta e oito por cento em volume, a vinte graus Celsius. É obtida pela destilação do mosto fermentado de cana-de-açúcar e pode ser adicionada de açúcares até seis gramas por litro, expressos em sacarose. Deve apresentar coeficiente de congêneres superior a duzentos miligramas por cem mililitros de álcool anidro e apresentar características sensoriais peculiares (BRASIL, 2003). Segundo Lima (1992) algumas cachaças destacavam-se pelas suas propriedades organolépticas peculiares que incluíam sabor, aroma e cor, resultados da fermentação, destilação e envelhecimento em tonéis de madeira.

Nos últimos anos, a cachaça tem sido cada vez mais consumida por todas as classes da população brasileira e, conforme Moraes (2001) seu consumo tem aumentado em alguns países da Europa, Estados Unidos e Japão sob a forma de coquetel, destacando-se a caipirinha. O Ministério da Agricultura, Pecuária e Abastecimento (MAPA) é o órgão responsável pela fiscalização e estabelecimento dos padrões de identidade e qualidade da cachaça e aguardente de cana, atualmente normatizado pela Instrução
Normativa $n^{\circ} 13 / 2005$.

A matéria-prima é fator primordial na qualidade do produto e na produtividade da indústria de cachaça e o produtor deve estar atento para a escolha das variedades de cana que melhor se adaptem às características do solo, período de safra e clima de sua região (MAIA et al., 1995).

Para a fabricação de cachaça, a matéria-prima utilizada é a cana-deaçúcar, sendo que outros ingredientes como o fubá, o farelo de arroz ou a farinha de soja sejam comumente adicionados ao caldo de cana como suplementos nutricionais para o fermento, sendo classificados como aditivos ou coadjuvantes da fermentação (OLIVEIRA, 1988).

Os principais fatores de qualidade e produtividade da cana-de-açúcar são: local e ambiente de cultivo, controle de pragas e doenças, variedades e planejamento agrícola. O planejamento está relacionado com os aspectos de maturação da cana, colheita, carregamento e transporte (CTP, 1998).

A cana-de-açúcar utilizada na produção da cachaça deve ser despalhada sem queima, apresentar colmos maduros e ser cortada rente ao nível do solo para evitar infestações de pragas e moléstias nos perfílios remanescentes e emissões de brotações aéreas. Além disso, o transporte deve ser feito de forma a preservar a integridade do colmo para evitar diminuição do rendimento (MINAS GERAIS, 2001; OLIVEIRA; MAGALHÃES, 2002).

Para realizar a moagem, a cana deve estar limpa, não conter palhas, resíduos de terras e outras impurezas que, além de aumentar o volume a ser prensado pelo engenho, são geralmente fontes de contaminação do caldo e posteriormente do fermento, reduzindo assim a capacidade de fermentação e, consequentemente, diminuindo a qualidade da cachaça (CPT, 1998). Além disso, a moagem deve ser realizada no prazo máximo de 24 horas após a colheita, e o equipamento deve estar bem regulado e com todas as suas partes e peças devidamente limpas (MINAS GERAIS, 2001).

Após a moagem, o caldo extraído deve passar por uma tela fina, para retenção de partículas sólidas e resíduos de bagaço e, em seguida, encaminhado para o decantador, onde ocorre a remoção das partículas sólidas remanescentes (MAIA; CAMPELO, 2005). Na sequência, o caldo que normalmente apresenta-se entre $18^{\circ}$ e $24^{\circ}$ Brix, deve ser acrescido de água para reduzir o Brix para $15^{\circ}$ ou $16^{\circ}$ (MAIA; CAMPELO, 2005). Durante a fermentação, a levedura, em condições anaeróbicas, metaboliza os açúcares do mosto, transformando-os em álcool, $\mathrm{CO} 2$ e outros compostos (YOKOYA, 1995). O mosto fermentado (vinho) segue para o destilador, 
onde ocorre a separação de diferentes compostos a diferentes temperaturas.

A otimização das condições de destilação é fundamental para a obtenção de uma bebida de boa qualidade, pois, a destilação além de separar, selecionar e concentrar os componentes do vinho pelo uso do calor, pode ainda promover algumas reações químicas termo-induzidas. Desta forma, os componentes voláteis do vinho, denominação do caldo fermentado, podem aumentar, diminuir e ainda originar novos componentes, fornecendo assim, características únicas à bebida (GUYMON, 1998). A destilação da cachaça pode ser executada por dois métodos: o contínuo que ocorre em coluna de destilação; e o método por batelada conduzido em alambiques, na sua grande maioria, de cobre (CHAVES; PÓVOA, 1992).

O produto da destilação do vinho por batelada em alambiques é dividido em três frações, denominadas: destilados de cabeça, de coração e de cauda. $\mathrm{O}$ destilado de cabeça, obtido na fase inicial de destilação que geralmente apresenta graduação alcoólica entre $65-70 \%$ v/v, é mais rico em substâncias mais voláteis como aldeídos, metanol e ésteres, assim como outros compostos menos voláteis, que podem também ser destilados juntamente com a mistura água-etanol, como os alcoóis superiores. O destilado de coração é a fração que corresponde à cachaça propriamente dita, devendo apresentar teor alcoólico em torno de $38-48 \% \mathrm{v} / \mathrm{v}$ e, finalmente, a fração cauda, que contém o restante de álcool então presente no vinho fermentado, bem como os compostos menos voláteis e outros que são arrastados pela mistura em destilação (BRASIL, 2003).

Segundo MAIA (1994), a fração de coração é recolhida até que o teor alcoólico do destilado, no barril de recolhimento, atinja o valor préestabelecido para a cachaça. A fração seguinte corresponde à cauda ou água fraca que é recolhida até o teor alcoólico atingir cerca de $14 \% \mathrm{v} / \mathrm{v}$. Na fração de cauda, também chamada de água fraca concentram-se os ácidos e furfural e também deve ser descartada. A fração cauda apresenta maior valor de acidez volátil e menor teor alcoólico (FURTADO, 1995).

Maia (1994) comenta que a separação das três frações do destilado deve ser feita através de "cortes" determinados pela temperatura dos vapores no topo do alambique (para o destilado de cabeça) ou pelo teor alcoólico do destilado, visando a separação do destilado de coração. A autora acrescenta ainda que, nesta etapa, a qualidade da cachaça depende da composição do vinho que é destilado, da geometria do alambique, de forma a assegurar um nível de refluxo que permita uma separação adequada dos componentes secundários, além da habilidade do operador para efetuar os "cortes" nos momentos adequados. Entretanto, a maioria dos produtores não dá a devida importância aos critérios a serem adotados na separação das frações.

Em 1989, Faria reafirmou que o alambique de cobre é o mais recomendado para a produção de cachaça devido à influência deste metal na qualidade da cachaça produzida, visto que o cobre catalisa também reações que retiram compostos sulfurados produzidos durante a fermentação e/ou provenientes da matéria-prima, evitando o aparecimento de defeitos sensoriais relacionados com tais compostos (FARIA; ELIZA; ROSSI, 1993).

A contaminação pelo cobre ocorre devido à formação nas paredes internas do alambique de uma substância denominada azinhavre, de fórmula química $\mathrm{CuCO} 3 \mathrm{Cu}(\mathrm{OH}) 2$, que é solubilizada pelos vapores ácidos. O teor máximo de cobre permitido nesse destilado, de acordo com a legislação vigente é de $5 \mathrm{mg} / \mathrm{L}$ de cachaça, sendo, porém, desejável sua eliminação, principalmente considerando-se seu papel na formação de carbamato de etila após o processo de destilação.

A higienização correta do alambique é necessária para evitar a formação do azinhavre e a consequente contaminação da cachaça por cobre, como também para promover seu efeito catalisador, de grande importância para a formação de ésteres e outros compostos desejáveis. Procedimentos como descartar os primeiros destilados no começo da safra e manter a serpentina do alambique cheia de água enquanto nenhum vinho é destilado asseguram, juntamente com a correta separação das frações, a produção de uma cachaça com menor contaminação por cobre (CANUTO, 2004).

Geralmente o produtor de cachaça de alambique não dispõe de um laboratório em sua fábrica para o acompanhamento detalhado de todo o processo. Entretanto, medições simples, como temperatura e grau Brix do mosto durante a fermentação e do destilado são extremamente úteis no controle do processo de fabricação da cachaça. Os pequenos produtores de cachaça precisam aprender a usar essas técnicas de análise para melhor acompanhar o processo, desenvolvendo assim, uma cultura de medida dos indicadores de qualidade e de produtividade (CPT, 1998).

$\mathrm{O}$ conhecimento da tecnologia da produção da cachaça favorece na melhoria da qualidade da bebida, podendo torná-la mais competitiva no mercado interno e mesmo internacional, sendo assim, comparada às melhores bebidas do mundo; porém, a capacitação técnica do setor ainda é um dos gargalos para a melhoria da sua qualidade. No entanto, a cadeia 
produtiva da cachaça não é tecnologicamente homogênea, havendo uma busca no desenvolvimento de tecnologias para aprimorar e controlar a qualidade e a padronização da bebida (MIRANDA, 2005).

\section{Boas Práticas de fabricação e a produção de cachaça}

Ao se fazer uma análise da produção da cachaça de alambique, podese citar como perigos químicos, comprovadamente importantes, os teores de carbamato de etila, de metanol, de metais pesados, tais como chumbo e arsênio e, como perigos físicos, a eventual presença de fragmentos de metais, insetos ou poeira na bebida. Estes perigos podem ser controlados por um projeto de Boas Práticas de Fabricação (BPF) atuante e, se o programa BPF não controlar o perigo, o sistema Análise de Perigos e Pontos Críticos de Controle (APPCC) o fará.As BPF são normas de procedimentos a fim de atingir um determinado padrão de identidade e qualidade de um produto, incluindo-se as bebidas (BRASIL, 1993). As BPF estabelecem os princípios gerais para a recepção de matérias-primas destinadas à produção de alimentos e bebidas (IETEC, 2002), além de condições de processamento mais adequadas para a implantação do sistema APPCC o que assegura, por sua vez, qualidade suficiente para o produto não oferecer riscos à saúde humana (ATHAYDE, 1999).

Pelo fato da cachaça apresentar uma elevada concentração de etanol (38$48 \% \mathrm{v} / \mathrm{v}$ ), não há o risco de desenvolvimento de microrganismos patogênicos, podendo-se, nesse aspecto, afirmar que seu consumo não apresenta perigo microbiológico, simplificando assim o plano APPCC/BPF, o que representa uma vantagem para o produtor. Além disso, devem-se levar em consideração outros fatores que interferem na qualidade química e sensorial da bebida, tais como a quantidade e a relação entre os compostos voláteis presentes. A variação na composição de voláteis presentes nas bebidas fermentodestiladas é influenciada pela cana de açúcar usada como matéria-prima (solo e clima, condições de colheita, armazenamento), pela fermentação (tipo de linhagem de levedura usada, grau de contaminação, temperatura e pH da fermentação) e pelo tipo, material do alambique e condução do processo de destilação. O controle das condições de destilação e do processo de envelhecimento (tipo de madeira, tempo de envelhecimento, tamanho do barril) também pode influenciar bastante na qualidade da cachaça.

Todos os fatores acima mencionados são certamente melhor controlados com um programa de BPF que trabalha a conscientização do produtor interessado em estabelecer este sistema de gestão de segurança alimentar na produção de cachaça de alambique.A falta de metodologia atualizada e uniforme de controle da qualidade da cachaça, como ocorre em outros países com outras bebidas, tem sido apontada como entrave à comercialização da nossa bebida no mercado interno e externo (ISIQUE et al., 2002; NAGATO et al., 2000; NASCIMENTO et al., 1998).

Segundo Miranda (2005), o aprimoramento da qualidade e da padronização da cachaça é essencial para que a cachaça atenda aos padrões internacionais e seja aceita pelo mercado exterior, favorecendo abertura e manutenção de um mercado exportador e agradando aos gostos mais exigentes das classes de maior poder aquisitivo, que estão dispostas a pagar mais caro por uma bebida de elevada qualidade.

\section{Material e Métodos}

As condições higiênico-sanitárias de quatro pequenas indústrias produtoras de cachaça de alambique do Estado de São Paulo foram avaliadas através de entrevistas in loco e aplicação de um questionário de verificação de Boas Práticas de Fabricação, antes e após a capacitação técnica dos respectivos produtores para melhoria da qualidade da cachaça.

Os quatro engenhos produtores de cachaça foram escolhidos entre os participantes do Projeto de Extensão de Capacitação de Pequenos Produtores de Cachaça do Estado de São Paulo, realizado anualmente desde 2004 pelo Departamento de Alimentos e Nutrição da Faculdade de Ciências Farmacêuticas da UNESP/Araraquara, SP denominado Encontro da Cadeia Produtiva de Cachaça. Este projeto tem o apoio do Serviço Brasileiro de Apoio às Micro e Pequenas Empresas, São Paulo (SEBRAE/SP) e do Sindicato Rural de Araraquara (FAESP-SENAR).O critério de escolha foi determinado mediante interesse dos produtores responsáveis pelos respectivos estabelecimentos em implantar as Boas Práticas de Fabricação em seus processos produtivos. Outros três produtores se interessaram pelo projeto, mas se desmotivaram a dar continuidade no trabalho no decorrer das atividades.

Nota-se que os dados obtidos através da aplicação dos questionários e observações convenientes, assim como as amostras de cachaças, foram coletados in loco por ocasião das visitas técnicas em quatro estabelecimentos produtores de cachaça aqui denominados A, B, C e D. Cada estabelecimento foi avaliado do ponto de vista de boas práticas de fabricação e da qualidade sensorial das bebidas em dois momentos: antes ( $\mathrm{t} 1$ ) e após ( $\mathrm{t} 2$ ) a capacitação 
dos produtores, respeitando um intervalo de 12 meses. Os resultados foram submetidos à Análise de Variância (ANOVA).

\section{Métodos}

Um roteiro de observação foi elaborado para verificação do cumprimento das Boas Práticas de Fabricação baseados nos itens avaliados pela Resolução da Diretoria Colegiada - RDC n ${ }^{\circ} 275$, de 21 de outubro de 2002, a qual dispõe sobre o Regulamento Técnico de Procedimentos Operacionais Padronizados aplicados aos Estabelecimentos Produtores/Industrializadores de Alimentos e a Lista de Verificação das Boas Práticas de Fabricação em Estabelecimentos Produtores/Industrializadores de Alimentos, e adaptados para a produção de cachaça. Foram incluídos neste questionário, os quesitos exigidos pelo Ministério da Agricultura, Pecuária e Abastecimento (MAPA) com o propósito de englobar os requisitos essenciais de higiene durante a produção de cachaça, bem como os aspectos relacionados às condições tecnológicas do engenho.

Os itens dos questionários foram agrupados por assunto, em 8 blocos, com base na metodologia utilizada pelo SENAI/SEBRAE (2000) e adaptado para este trabalho, conforme necessidade observada nas visitas aos estabelecimentos produtores de cachaça e de acordo com os aspectos abordados durante as consultorias técnicas, sendo eles:EI - Edificações e Instalações;OL - Organização e Limpeza;CPR - Controle de Pragas e Resíduos;AE - Água e efluentes;MP - Matérias-primas;M - Manutenção;HP - Higiene Pessoal;CQ-Controle de Qualidade.Os itens do questionário foram classificados conforme sugerido por Amaral (2001) e Pinto (2001) como:

- Imprescindíveis (I): itens críticos para a proteção da saúde do consumidor e qualidade da cachaça que necessitam de correção imediata quando não atendidos;

- Necessários $(\mathrm{N})$ : itens de média criticidade, ou seja, não essenciais para o controle efetivo do risco à saúde do consumidor e qualidade, mas que contribuem para a sua ocorrência, podendo aguardar um tempo maior para sua adequação e;

- Recomendáveis (R): itens que não oferecem risco à saúde do consumidor, mas que atendem aos requisitos legais das BPF e qualidade.

- Amaral (2001) e Tomichet al. (2005) determinaram que cada item atendido foi marcado como sim $(\mathrm{S})$; não $(\mathrm{N})$ e não atendido ou não se aplica (NA) quando o item não for pertinente à avaliação do estabelecimento.

Além disso, as condições operacionais foram analisadas quantitativamente, adaptando a metodologia de Amaral (2001) e Pinto (2001), sendo que os itens que receberam (S) e (NA) foram pontuados conforme suas classificações e os itens que receberam (N) não foram pontuados. Os itens imprescindíveis receberam pontuação (4), os necessários, pontuação (2) e os recomendáveis, pontuação (1).Os cálculos das pontuações dos blocos e dos estabelecimentos foram feitos conforme proposto por Tomichet al. (2005) e utilizado por Vilela (2005).

\section{Resultados e Discussão}

\section{Avaliação de Boas Práticas de Fabricação}

As atividades iniciaram-se após a elaboração do questionário usado para verificar as Boas Práticas de Fabricação de micro e/ou pequenas empresas produtoras de cachaça do interior de São Paulo.Cada um dos quatro estabelecimentos recebeu individualmente uma visita técnica e o questionário foi aplicado (T1) in loco, na mesma ocasião em que foram registradas as observações pertinentes às boas práticas de fabricação.Os questionários foram analisados e serviram como referência para o trabalho de consultoria tecnológica que cada estabelecimento recebeu em parceria com o SEBRAE-SP, com o programa SEBRAETec.

Foi elaborado um cronograma de trabalho, em que, mensalmente, em novas visitas técnicas as etapas eram trabalhadas com a finalidade de proporcionar melhorias tecnológicas nos estabelecimentos e processos envolvidos com a produção da cachaça.Aspectos relacionados à higienização das instalações, equipamentos, fermentação, destilação, envelhecimento, padronização, controle de qualidade e análise sensorial foram abordados conforme a necessidade particular de cada estabelecimento.Após o período de 12 meses de interação, um novo questionário foi aplicado (T2) para que pudesse ser comparado com o aplicado no início das atividades (T1).A

Figura 1- representa a contribuição que cada bloco oferece na elaboração da nota do estabelecimento.

Observa-se que o bloco de maior impacto na avaliação de Boas Práticas de Fabricação é o bloco 6, que trata sobre Manutenção, seguido pelo bloco 4, que aborda aspectos relacionados à Água e Efluentes; pelo bloco 5, que 
Figura 1 - Peso dos blocos em porcentagem.

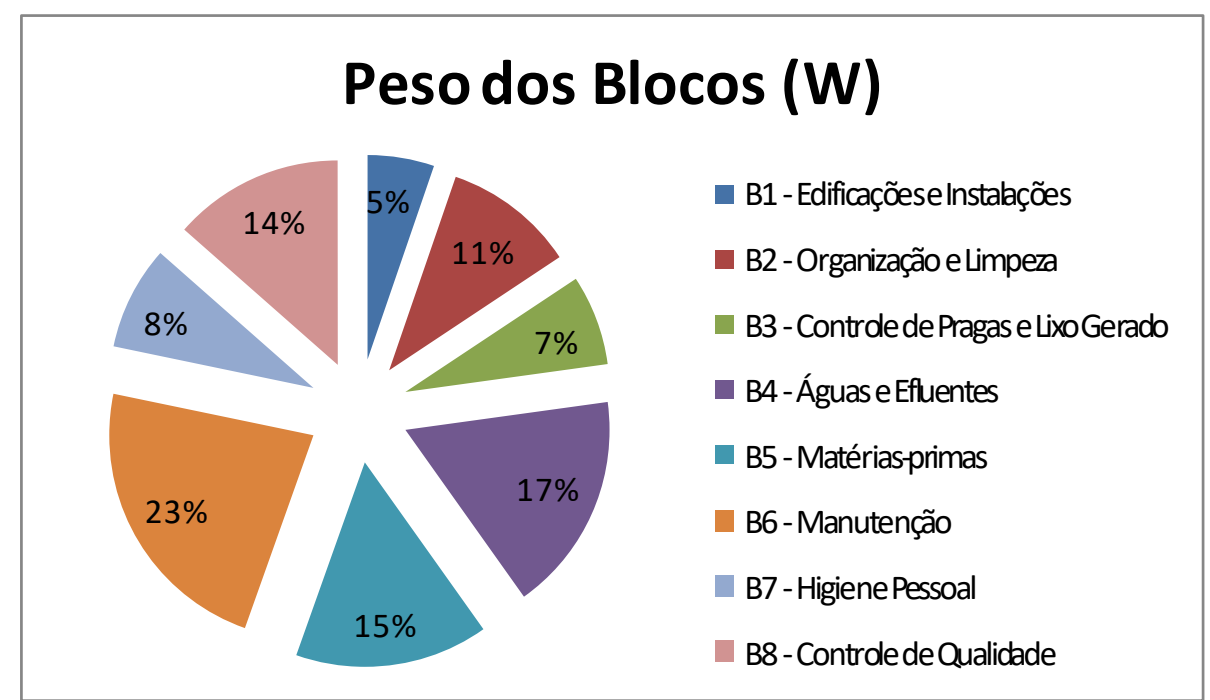

Fonte: Elaborado pelos autores.

aborda qualidade e manuseio de Matérias-primas e pelo bloco 8 que avalia os aspectos envolvidos com o Controle de Qualidade.

Conforme constatado no trabalho de Vilela (2005), para a avaliação de fábricas de cachaça o ideal seria elaborar e aplicar diferentes listas de verificação, adaptadas às características próprias de produção de cachaça da região. Sendo assim, para o desenvolvimento do presente estudo já foram tomadas as providências de alterações que se julgaram necessárias ao longo de visitas anteriores a diferentes fábricas de cachaça.Desta forma, questões relacionadas à gestão e tratamento de águas e efluentes não foram responsáveis por maiores contribuições das notas no estudo de Vilela (2005), no qual os blocos que mais influenciaram nas notas das fábricas foram aqueles que abordavam aspectos relacionados à manutenção dos equipamentos e utensílios; à qualidade, recepção e armazenamento das matérias-primas, ingredientes e insumos e ao controle produtivo e garantia da qualidade, visto que o peso dos blocos e a quantidade de itens imprescindíveis em cada um dos blocos são diferentes.

Em se tratando das notas obtidas em cada estabelecimento produtor de cachaça, elas podem ser observadas na Figura 2. Para efeito de comparação, estão representadas como T1 e T2 as notas observadas ao início das atividades e após o encerramento das mesmas, respectivamente.
Figura 2 - Nota do estabelecimento produtor de cachaça no início (T1) e ao final das atividades (T2) de implantação de BPF.

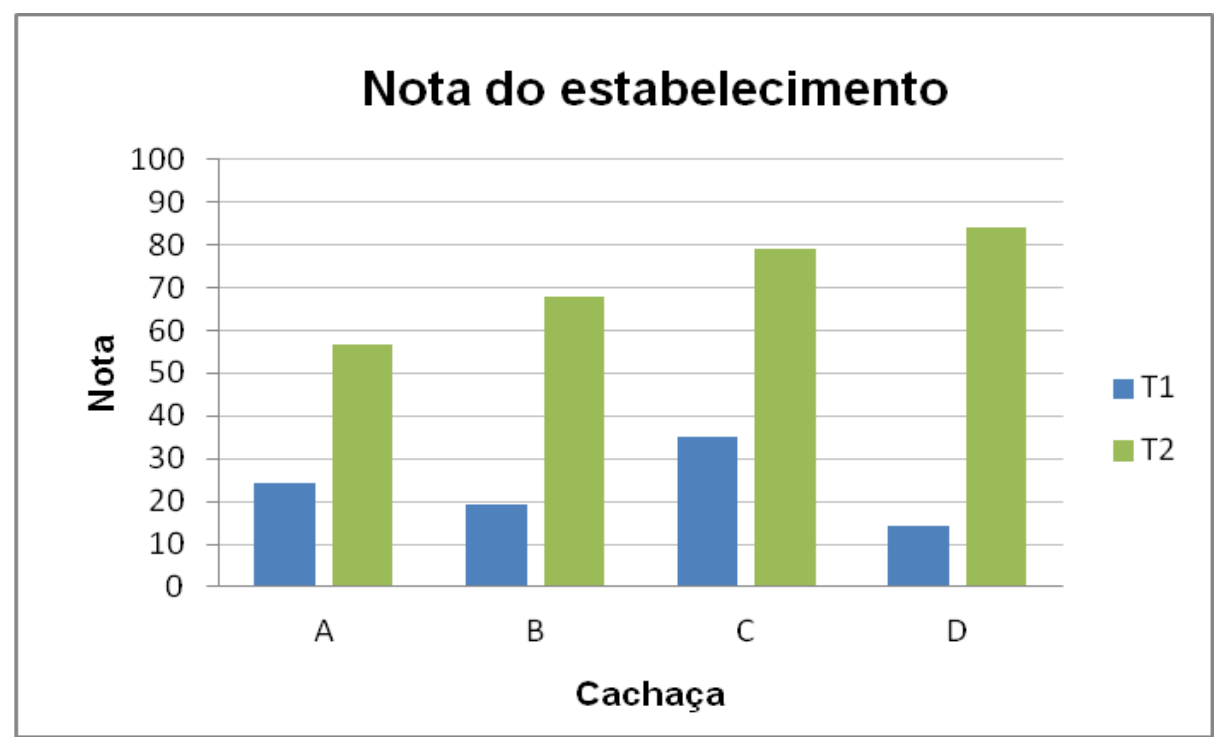

Fonte: Elaborado pelos autores.

Assim, as figuras 3 a 6 ilustram a pontuação ponderada de cada estabelecimento e a contribuição de cada bloco para a totalização das notas. Especificamente, na Figura 3, encontram-se os resultados do estabelecimento produtor da cachaça $A$. Nota-se que houve aumento considerável da pontuação total do estabelecimento produtor $\mathrm{A}$, sendo que os blocos sobre Manutenção (Bloco 6), Águas e Efluentes (Bloco 4), Organização e Limpeza (Bloco 2) e Controle de Qualidade (Bloco 8) foram os que mais contribuíram para a melhoria da nota geral.

O mesmo pode ser observado na Figura 4, que retrata a contribuição dos blocos para a pontuação do estabelecimento B. Cabe, entretanto, destacar que as melhorias foram maiores neste produtor que no produtor $\mathrm{A}$, visto que o salto da nota inicial para a nota final foi consideravelmente maior.

No caso do estabelecimento C, observa-se que o bloco de maior contribuição da nota após as consultorias técnicas foi o que aborda Higiene Pessoal (bloco 7), fato que não ocorria no momento da aplicação Pessoal (bloco 7), fato que não ocorria no momento da aplicação do primeiro questionário (Figura 5).

Além disso, os outros blocos que mais contribuíram para a nota deste estabelecimento foram os blocos 4, que aborda Águas e Efluentes; o bloco 6 de Manutenção e o bloco 5 de Matérias-primas.A pontuação ponderada 
Figura 3 - Pontuação ponderada por bloco do estabelecimento produtor A

\section{Pontuação Ponderada do Bloco (PPB)- A}

B8 - Controle de Qualidade

B7 - HigienePessoa

B6 - Manutenção

B5 - Matérias-primas

B4-Águas e Efluentes

B3 - Controle de Pragas e Lixo Gerado

B2 - Organizaçãoe Limpeza

B1-Edificações e Instalações

Total

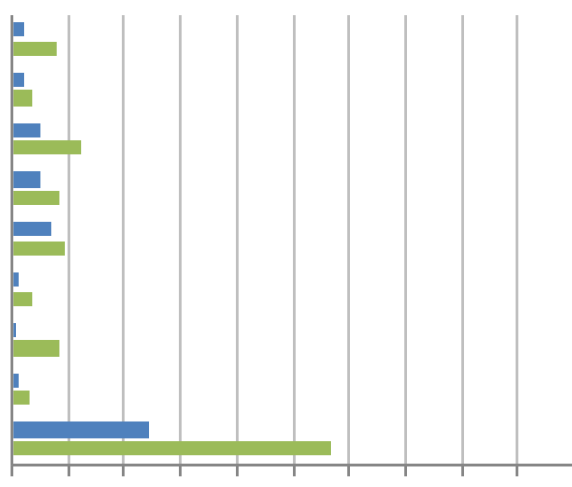

T1

T2

$\begin{array}{lllllllllll}0 & 10 & 20 & 30 & 40 & 50 & 60 & 70 & 80 & 90 & 100\end{array}$ Pontuação ponderada dobloco (PPB)

Fonte: Elaborado pelos autores.

Figura 4 - Pontuação ponderada por bloco do estabelecimento produtor da cachaça B antes (T1) e após (T2) implantação de BPF.

\section{Pontuação Ponderada do Bloco (PPB)- B}

B8 - ControledeQualidade

B7 - HigienePesso

B6-Manutenção

B5 - Matérias-primas

B4 - Águas eEfluentes

B3-Controle de Pragas e LixoGerado

B2 - Organizaçãoe Limpeza

B1 - Edificações e Instalações

Total

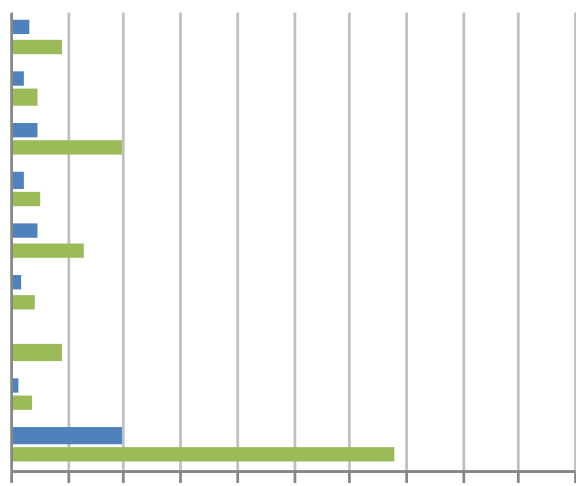

$\begin{array}{lllllllllll}0 & 10 & 20 & 30 & 40 & 50 & 60 & 70 & 80 & 90 & 100\end{array}$ Pontuação ponderada dobloco (PPB)

Fonte: Elaborado pelos autores.
Figura 5 - Pontuação ponderada por blocos do estabelecimento produtor da cachaça C no início (T1) e ao final das atividades (T2).

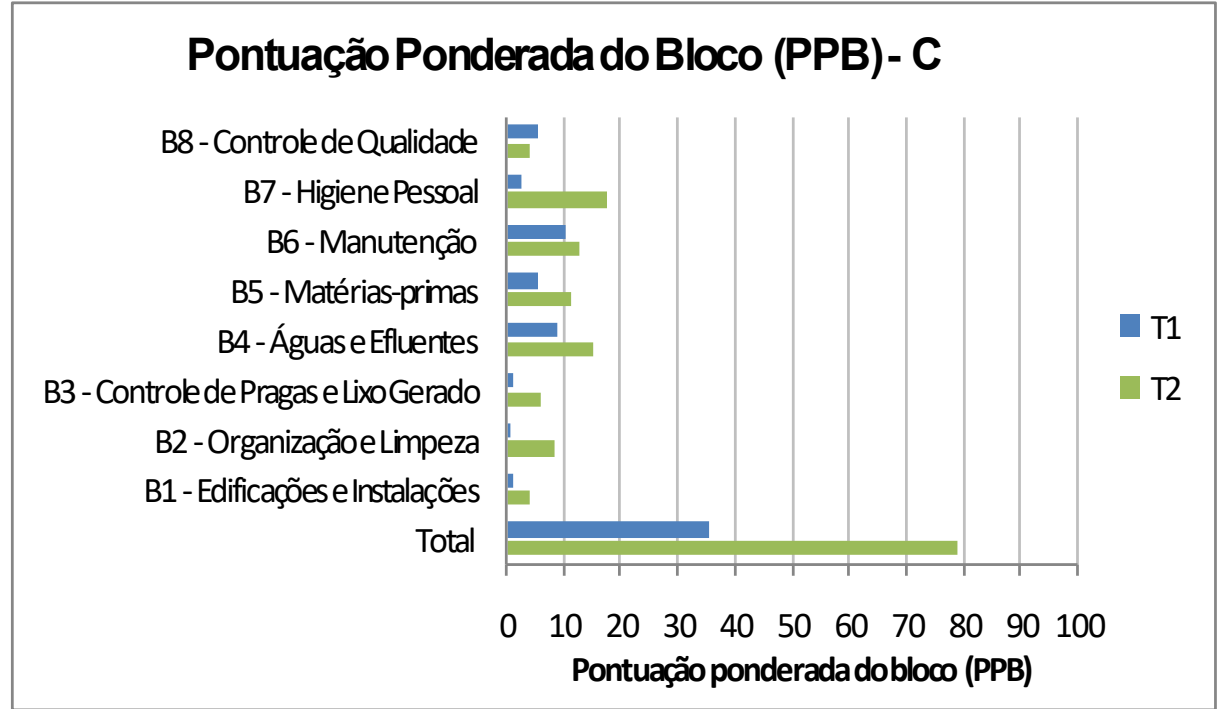

Fonte: Elaborado pelos autores.

do estabelecimento produtor da cachaça D pode ser observada na Figura 6 sendo possível dizer que o estabelecimento não fabricava a bebida segundo os critérios de BPF e passou então a fabricar, resultando melhora em todos os aspectos trabalhados e elevando consideravelmente a nota geral.

Observa-se ainda haver uma similaridade das contribuições dos blocos envolvendo aspectos relacionados a Águas e Efluentes, Controle de Pragas e Lixo Gerado; Organização e Limpeza; e Edificações e Instalações.Quanto ao quesito Águas e Efluentes, notou-se que os estabelecimentos passaram a realizar ações imprescindíveis para o aumento da nota de BPF, como a limpeza periódica de reservatórios e manutenção dos mesmos fechados. Além disso, a água utilizada na produção passou a ser analisada por $75 \%$ dos produtores, não fornecendo, portanto, os riscos de contaminação antes observados.

As principais mudanças observadas quanto ao Controle de Pragas e Lixo Gerado foi que os resíduos gerados durante a fabricação passoram a ter destino adequado; a fábrica passou a ter coletores de lixo em quantidade suficiente e os produtos utilizados para combater pragas e insetos passaram a ter local específico para serem armazenados.

As principais mudanças observadas quanto ao Controle de Pragas e Lixo Gerado foi que os resíduos gerados durante a fabricação passou a ter destino 
Figura 6 - Pontuação ponderada por blocos do estabelecimento produtor D antes (T1) e após (T2) implantação de BFP.

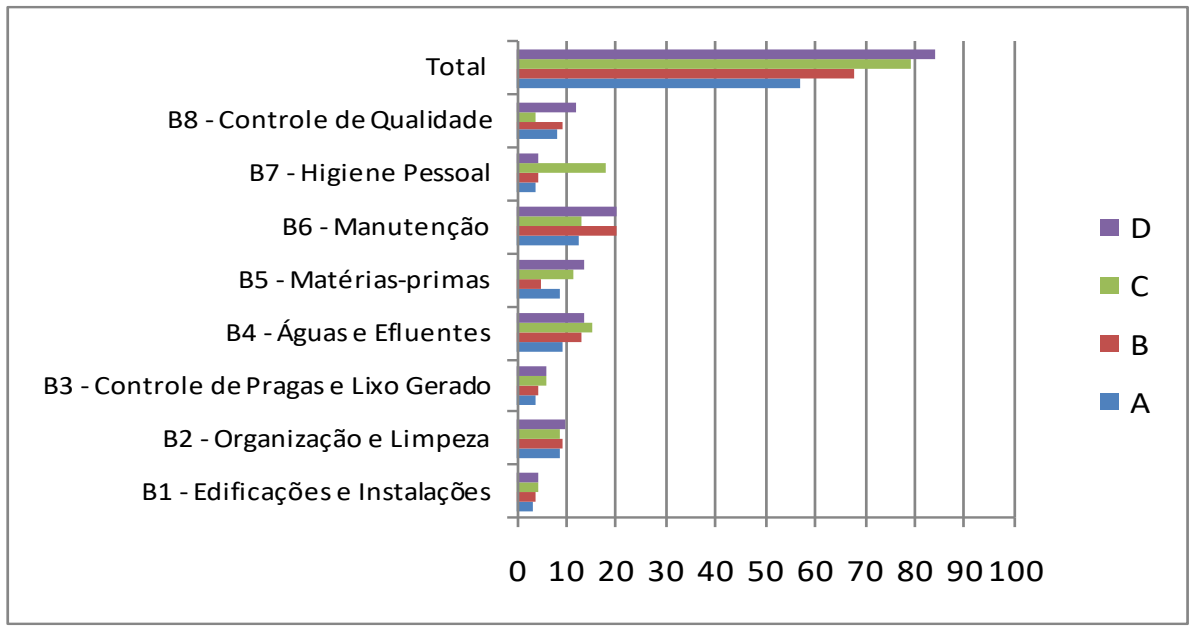

Fonte: Elaborado pelos autores.

A Figura 7 representa a contribuição de cada bloco na composição das notas dos estabelecimentos produtores de cachaça (A, B, C e D).

Figura 7 - Contribuição por bloco na nota dos estabelecimentos que receberam.

\section{Pontuação Ponderada do Bloco (PPB)- D}

B8-ControledeQualidade

B7-HigienePessoal

B6-Manutenção

B5-Matérias-primas

B4-Águas eEfluentes

B3 - ControledePragas e Lixo Gerado

B2 - Organizaçãoe Limpeza

B1-Edificações e Instalações

Total

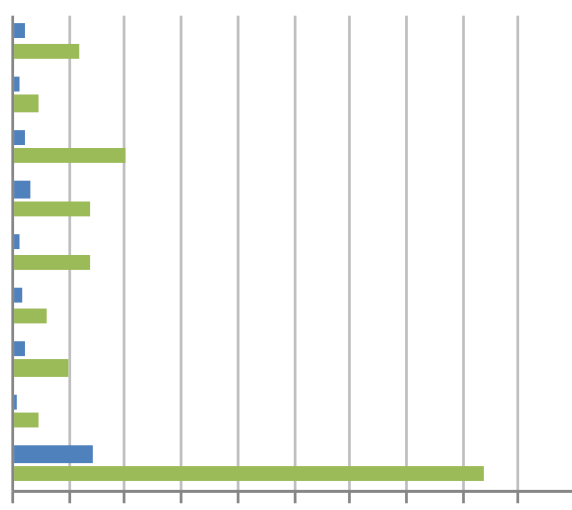

$\begin{array}{lllllllllll}0 & 10 & 20 & 30 & 40 & 50 & 60 & 70 & 80 & 90 & 100\end{array}$ Pontuação ponderada dobloco (PPB)

Fonte: Elaborado pelos autores. adequado; a fábrica passou a ter coletores de lixo em quantidade suficiente e os produtos utilizados para combater pragas e insetos passaram a ter local específico para serem armazenados.

O Bloco sobre Organização e Limpeza passou a contribuir efetivamente nas notas dos estabelecimentos devido à adoção de práticas antes não realizadas, como limpeza e higienização de utensílios e equipamentos envolvidos nas etapas de produção, assim como relatado por Vilela (2005). Além disso, 75\% dos estabelecimentos passaram a ter portas e janelas com telas de proteção e $100 \%$ passaram a ter o acesso à área fabril pavimentado, contribuindo assim com a pontuação do bloco que relaciona itens de Edificações e Instalações.

\section{Classificação dos estabelecimentos e registro}

Um dos instrumentos utilizados pra avaliar a qualidade foi a classificação dos estabelecimentos e registro. Indica-se que as classificações dos estabelecimentos quanto ao cumprimento das BPF foram baseadas na RDC $\mathrm{n}^{\circ} 275$, de 21 de outubro de 2002, sendo que, foram classificados como Grupo 1 (bons) os estabelecimentos que atenderam de 76 a $100 \%$ dos itens avaliados; Grupo 2 (regulares) aqueles que atenderam de 51 a $75 \%$ dos itens e Grupo 3 (ruins) os que atenderam de 0 a $50 \%$ dos itens. Com base no exposto, a Tabela 1 traz a classificação de cada estabelecimento em relação ao atendimento das $\mathrm{BPF}$.

Vilela (2005) em seu estudo observou que a nota média de BPF nas fábricas de cachaça avaliadas foi de 59,6, evidenciando que o critério de BPF ainda não é amplamente aplicado à produção de cachaça e que condições tecnológicas de processamento adequadas, relativas à qualidade da bebida não estão sendo seguidas.

Durante a avaliação, os produtores foram questionados também em relação à regularização do estabelecimento e dos produtos no MAPA, sendo observado que a realidade das fábricas antes da capacitação técnica dos micro e pequenos produtores (T1) era que nenhuma possuía registro, e nem os respectivos produtos produzidos.Após o período de capacitação técnica e, consequentes melhorias nas fábricas devido à implantação de BPF, observou-se que apenas um estabelecimento ainda não fez a solicitação dos devidos registros.

Embora a legislação não obrigue a indústria a implantar um programa de gestão da qualidade como BPF, observa-se que nas fábricas de cachaça de 
alambique com registro os produtores têm um comprometimento maior com conceitos de BPF do que os produtores das fábricas sem registro (VILELA, 2005), corroborando os resultados observados neste trabalho.

Tabela 1 - Classificação do estabelecimento produtor de cachaça em relação à nota obtida nos questionários em dois momentos (T1 e T2).

\begin{tabular}{ccccccc}
\hline \multirow{2}{*}{ Cachaça a } & \multicolumn{3}{c}{$\mathrm{T}_{1}$} & \multicolumn{3}{c}{$\mathrm{T}_{2}$} \\
\cline { 2 - 7 } & Nota & Classificação & Grupo & Nota & Classificação & Grupo \\
\hline A & 24,19 & Ruim & 3 & 56,65 & Regular & 2 \\
B & 19,41 & Ruim & 3 & 67,87 & Regular & 2 \\
C & 35,25 & Ruim & 3 & 78,94 & Bom & 1 \\
D & 14,39 & Ruim & 3 & 84 & Bom & 1 \\
\hline
\end{tabular}

\section{Análise sensorial}

Fonte: Elaborado pelos autores.

Para a avaliação sensorial foi realizado o teste sensorial de preferência global por parte de consumidores com base em escala hedônica. Os testes foram realizados durante as sessões de análise sensorial do IV e V Concurso Paulista de Cachaça de Alambique, promovido pelo Departamento de Alimentos e Nutrição da Faculdade de Ciências Farmacêuticas da Universidade Estadual Paulista - UNESP, Araraquara, SP.

$\mathrm{Na}$ ocasião, as amostras codificadas com três dígitos aleatórios, foram apresentadas aos provadores em copos transparentes, sendo cada amostra avaliada por 30 diferentes provadores, aos quais eram oferecidos água e bolacha de água e sal entre uma amostra e outra, posto que cada provador recebia 4 amostras para serem avaliadas.

As análises aconteceram num stand montado na praça de alimentação do Shopping Lupo (2009) e no Restaurante Gauchopp (2009 e 2010). Ambos localizados na cidade de Araraquara, SP e escolhidos pelo diversificado fluxo de clientes, potenciais provadores de cachaça, através da implementação do Método sensorial afetivo

Após análise sensorial das cachaças em relação ao aspecto global da bebida observou-se haver aumento significativo $(p \geq 0,01)$ das notas médias de todas as amostras avaliadas no segundo momento (T2), quando comparadas com as notas obtidas no início das atividades de capacitação técnica (Figura 8).Cabe ressaltar ainda que todas as cachaças avaliadas não eram envelhecidas e as amostras representavam fielmente o produto comercializado pelo produtor.

Figura 8 - Avaliação sensorial das cachaças produzidas nos estabelecimentos antes (T1) e após (T2) capacitação técnica para implantação de BPF.

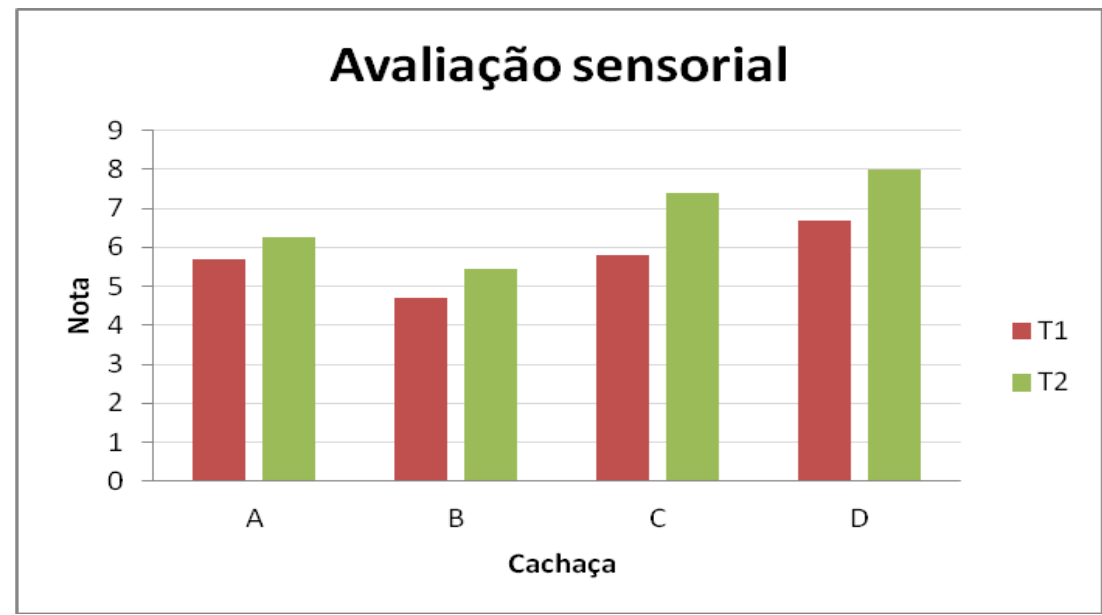

Fonte: Elaborado pelos autores.

Figura 9 - Relação entre as nota das análises sensoriais das cachaças e as notas de BPF dos respectivos estabelecimentos produtores.

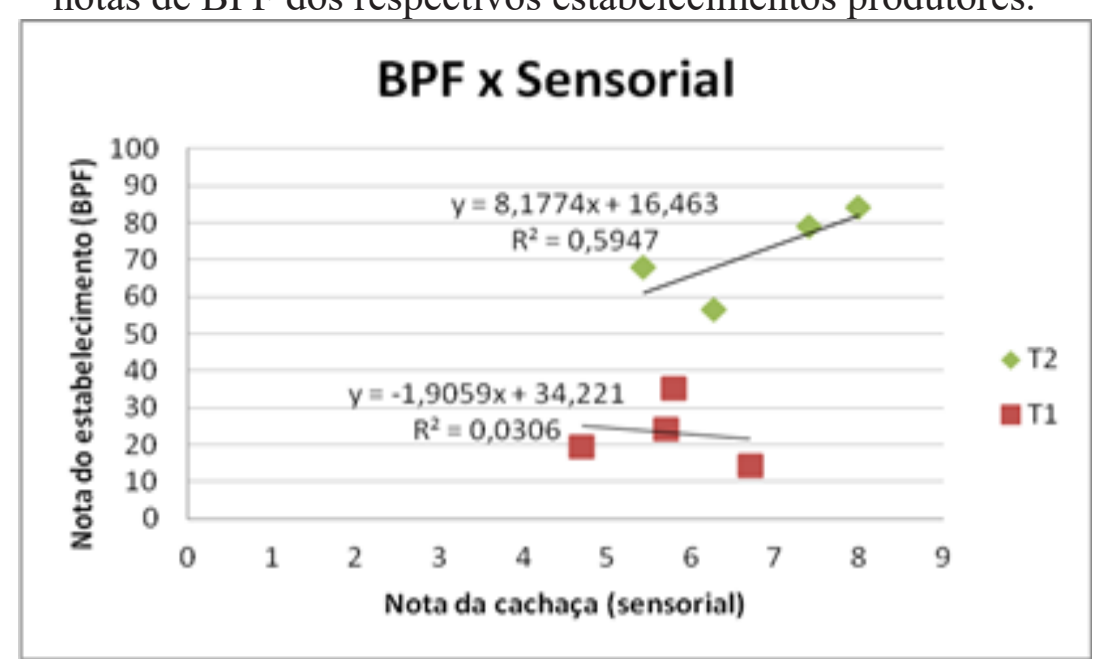

Fonte: Elaborado pelos autores.

A Figura 9 apresenta a correlação entre as notas da avaliação sensorial das cachaças analisadas e as notas dos estabelecimentos em relação ao 
cumprimento de BPF, antes e após a capacitação técnica in loco.

Nota-se que há uma tendência de correlação significativa entre o aumento das notas de BPF e o aumento da qualidade sensorial das cachaças após a capacitação técnica dos produtores, sendo a correlação no tempo T2 (após o treinamento) maior quando comparada com as amostras do tempo $\mathrm{T} 1$ (antes do treinamento).

\section{Conclusões}

Os estabelecimentos produtores de cachaça foram inicialmente classificados em sua totalidade como "ruins" (Grupo 3) com base na Resolução RDC n ${ }^{\circ} 275$, de 21 de outubro de 2002. Após a interação via consultorias tecnológicas com os produtores, os mesmos estabelecimentos foram reavaliados e os resultados mostraram que $50 \%$ passaram a ser classificados como "regulares" (Grupo 2) e 50\% como "bons" (Grupo 1).

A adoção de Boas Práticas de Fabricação pelos produtores de cachaça representou contribuição fundamental para o registro dos estabelecimentos junto aos órgãos competentes. Também registra-se a importância de possíveis ganhos ambientais, pois a implantação das Boas Práticas obriga que os produtores tratem seus efluentes, reduzindo os impactos no meio ambiente.

Houve correlação direta e significativa entre a adoção das Boas Práticas de Fabricação e a qualidade sensorial das cachaças, que resultou maior após conclusão da capacitação técnica para implantação de BPF.

\section{Referências Bibliográficas}

ANJOS, J. P. DOS et al. Identificação do carbamato de etila durante o armazenamento da cachaça em tonel de carvalho (quercussp) e recipiente de vidro. Química Nova, v. 34, n. 5, p. 874-878, 2011.

ASSOCIAÇÃO BRASILEIRA DE BEBIDAS. Programa Brasileiro de Desenvolvimento da Aguardente de Cana. São Paulo, 2013. Disponível em: <http://www.abrabe.org.br>. Acesso em: 18 jul. 2013.

AMARAL, C. A. A. Parâmetros para a avaliação da qualidade higiênicosanitária de uma unidade de alimentação e nutrição. 2001. 228 p. Dissertação (Mestrado em Ciências de Alimentos) - Faculdade de Farmácia,
Universidade Federal de Minas Gerais, Belo Horizonte, 2001.

ATHAYDE, A. Sistemas GMP e HACCP garantem a produção de alimentos inócuos. Engenharia de Alimentos, ano 5, n. 23, p. 13-17, 1999.

BARBOZA, R. A. B.; FARIA, J. B. Inovação em pequena empresa: um estudo com produtores de cachaça. Rev. Ciênc. Ext. v.11, n.2, p.38-55, 2015.

BARBOZA, R. A. B. et al. Efeito do envelhecimento na qualidade da cachaça produzida por pequenos produtores. Rev. Ciênc. Ext. v.6, n.2, p.46, 2010.

BORTOLETTO, A. M.; ALCARDE, A. R. Assessment of chemical quality of Brazilian sugar cane spirits and cachaças.FoodControl, v. 54, p. 1-6, ago. 2015.

BRASIL. Ministério da Agricultura, Pecuária e Abastecimento. Instrução Normativa ${ }^{\circ} 13$ de 29 de junho de 2005. Diário Oficial [da] União. Brasília, 30 de junho de 2005.

Ministério da Agricultura. Decreto n 4.851 de 02 de outubro de 2003. Altera dispositivos do Regulamento aprovado pelo Decreto $\mathrm{n}^{\circ} 2.314$, de 4 de setembro de 1997, que dispõe sobre a padronização, a classificação, o registro, a inspeção, a produção e a fiscalização de bebidas.

CARNEIRO, J. DE D. S. et al. Opiniões e atitudes dos consumidores em relação a embalagens e rótulos de cachaça. Ciência e Tecnologia de Alimentos, v. 30, n. 3, p. 669-673, set. 2010.

CANUTO, M. H. Metais em aguardentes mineiras fabricadas artesanalmente na região do Alto vale do Jequitinhonha. 2004. 148 p. Dissertação (Mestrado em Química Orgânica). Instituto de Ciências Exatas, Universidade Federal de Minas Gerais, Belo Horizonte, 2004.

CHAVES, J. B.; PÓVOA, M. E. B. A qualidade da aguardente de cana-deaçúcar. In: MUTTON, M. J. R.; MUTTON, M. A. Aguardente de cana: produção e qualidade. Jaboticabal: FUNEP, 1992, p. 93-132. 
CPT (Centro de Produções Técnicas). Cachaça: produção artesanal de qualidade. Viçosa: CPT, 1998. 78 p.

FARIA, J. B.; ELIZA, R.; ROSSI, E. A. Compostos sulfurados e a qualidade das aguardentes de cana (Saccharumofficinarum, L.). Ciência e Tecnologia de Alimentos, v. 13, n. 1, p. 90-93, 1993.

FERNANDES,A.P. etal. Pattern recognition applied to mineral characterization of Brazilian coffees and sugar-cane spirits. SpectrochimicaActa Part B: Atomic Spectroscopy, v. 60, n. 5, p. 717-724, jun. 2005.

FURTADO, S.M.B. Avaliação sensorial descritiva de aguardente de cana: influência da composição em suas características sensoriais e correlação entre as medidas sensoriais e físico-químicas. 1995.99 p. Tese (Doutorado em Tecnologia de Alimentos) - Faculdade de Engenharia de Alimentos, Universidade Estadual de Campinas, Campinas, 1995.

GUYMON, J. F. Chemical aspects of distiling wines into brandy. In: WEBB, A. D. (Ed) Chemistry of Winemaking. Washington: 1974. p. 232-253 apud BOZA, Y.; HORII, J. Influência da Destilação sobre a Composição e a Qualidade Sensorial da Aguardente de Cana-de-açúcar. Ciência e Tecnologia de Alimentos, v. 18, n. 4, p. 391-396, 1998.

ISIQUE, W. D.; LIMA-NETO, B. S.; FRANCO, D. W. A qualidade da cachaça, uma opinião para discussão. O Engarrafador Moderno, n. 98, p. 32-36, 2002.

LIMA, U. de A. Produção nacional de cachaças e potencialidade dos mercados internos e externos. In: MUTTON, M. J. R.; MUTTON, M. A. (Ed.) Aguardente de cana: produção e qualidade. Jaboticabal: Fundação Estadual de Pesquisas Agronômicas, 1992. p. 151-163.

LOUREIRO, I. M. A. L. O ambiente informacional na aplicação do regulamento de avaliação da conformidade do Inmetro nas empresas: um estudo do segmento da cachaça. 2008. Dissertação (Mestrado em Ciência da Informação) - Instituto Brasileiro de Informação em Ciência e Tecnologia. Universidade Federal Fluminense, Niterói.
MAIA, A. B. R. A.; CAMPELO, E. A. P. Tecnologia da Cachaça de Alambique. Belo Horizonte: SEBRAE/MG; SINDIBEBIDAS, 2005. 129 p.

MAIA, A. B.; RIBEIRO, J. C. G.; SILVEIRA, L. C. I. $1^{\circ}$ Curso AMPAQ de produção artesanal de aguardente de qualidade. Belo Horizonte: AMPAQ, $1995106 \mathrm{p}$.

MACHADO, A. M. D. R. et al. Contamination of cachaça by PAHs from storage containers. FoodChemistry, v. 146, p. 65-70, mar. 2014.

MINAS GERAIS. Lei 13949 de 11 de julho de 2001. Estabelece o padrão de identidade e as características da cachaça de Minas e dá outras providências. Disponível em: $<$ http://www.almg.gov.br/index. asp? grupo $=$ legislacao \&diretorio $=$ njmg $\&$ arquivo $=$ legislacao mineira $>$ Acesso em: 20 out. 2009 .

MIRANDA, M. B. de. Avaliação físico-química de cachaças comerciais e estudo da influência da irradiação sobre a qualidade da bebida em tonéis de carvalho. 2005. 70 p. Dissertação (Mestrado em Ciência e Tecnologia de Alimentos). Universidade de São Paulo - Escola Superior de Agricultura "Luiz de Queiróz". Piracicaba, 2005.

MONTEIRO, T. M. et al. Development of a certified reference material for cachaça: an effective material for quality assurance. Accreditation and Quality Assurance, v. 18, n. 3, p. 197-206, 11 jun. 2013.

NAGATO, L. A. F.; YONAMINE, M.; PENTEADO, M. V. C. Quantification of ethyl carbamate (EC) by gas chromatography and mass spectrometric detection in distilled spirits. Alimentaria, n. 311, p. 31-36, 2000.

NASCIMENTO, R. F.; CERRONI, J. L.; CARDOSO, D. R.; LIMA-NETO, B. S.; FRANCO, D. W. Comparação dos métodos oficiais de análise e cromatográficos para a determinação dos teores de aldeídos e ácidos em bebidas alcoólicas. Ciência e Tecnologia e Alimentos. Campinas, v. 18, n. 3, p. 350-355, 1998.

OLIVEIRA, S. G.; MAGALHÃES, M. A. Procedimentos para produção 
da cachaça artesanal de Minas regulamentados pelo Decreto n ${ }^{\circ} 42644$ de 05/06/2002. Informe agropecuário, v. 23, n. 217, p. 78-83, 2002.

OLIVEIRA, E. S. Efeito da adição de suplementos nutricionais na fermentação alcoólica de melaço de cana-de-açúcar em diferentes temperaturas. 1988. 63 p. Dissertação (Mestrado em Ciência e Tecnologia de Alimentos) - Faculdade de Engenharia de Alimentos, Universidade Federal de Viçosa. Viçosa, 1988

PEREIRA, A. F. Suplementação de nitrogênio sobre a fermentação alcoólica para produção de cachaça, cerveja e vinho. 2007. Dissertação (Mestrado em Ciência e Tecnologia de Alimentos) - Universidade Federal da Viçosa, Viçosa.

PINTO, R. G. Avaliação das boas práticas de fabricação e da qualidade microbiológica na produção de pão de queijo. 2001. 179 p. Dissertação (Mestrado em Ciência de Alimentos) - Faculdade de Farmácia, Universidade Federal de Minas Gerais, Belo Horizonte, 2001

PRIBANIC, M. A. A cachaça capixaba: um estudo sobre barreiras à internacionalização. 2011. Dissertação (Mestrado em Administração) Fundação Instituto Capixaba de Pesquisa em Contabilidade, Economia e Finanças, Vitória.

SERVIÇO BRASILEIRO DE APOIO A MICRO E PEQUENA EMPRESA DO ESTADO DE SÃO PAULO. Cachaça: um negócio brasileiro. 2. ed. São Paulo: Ramos Data Gráfica e Editora, 2010.

SERVIÇO NACIONAL DE APRENDIZAGEM INDUSTRIAL - SENAI / SERVIÇO BRASILEIRO DE APOIO ÀS MICRO E PEQUENAS EMPRESAS - SEBRAE. Guia para verificação do sistema APPCC. Série qualidade e segurança alimentar. Projeto APPCC indústria. Convênio CNI/ SENAI/SEBRAE. 2000. 2. ed. Brasília: SENAI/DN. 61p.

TOMICH, R. G. P.; TOMICH, T. R.; AMARAL, C. A. A.; JUNQUEIRA, R. G.; PEREIRA, A. J. G. Metodologia para avaliação das Boas Práticas de Fabricação em indústrias de pão de queijo. Ciência e Tecnologia de Alimentos.v. 25, n. 1, p. 115-120. 2005.

VILELA, A.F. Estudo da adequação de critérios de Boas Práticas de Fabricação na avaliação de fábricas de cachaça de alambique. 2005.

96 p. Dissertação (Mestrado em Ciência de Alimentos) - Faculdade de Farmácia, Universidade Federal de Minas Gerais, Belo Horizonte, 2005.

YOKOYA, F. Fabricação de aguardente de cana. Campinas: Fundação Tropical de Pesquisas e Tecnologia “André Tosello", 1995. 92p. 